\title{
Electrochemotherapy in head and neck cancer: A review of an emerging cancer treatment (Review)
}

\author{
ARMANDO DE VIRGILIO ${ }^{1}$, MASSIMO RALLI ${ }^{2}$, LUCIA LONGO $^{3}$, PATRIZIA MANCINI ${ }^{3}$,

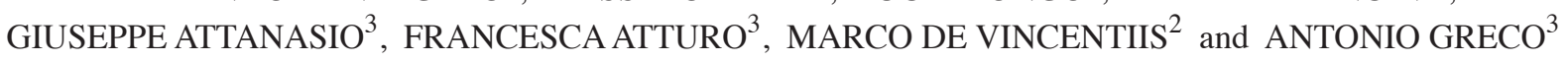 \\ ${ }^{1}$ Department of Otolaryngology, Humanitas Clinical and Research Center, I-20089 Milan; \\ Departments of ${ }^{2}$ Oral and Maxillofacial Sciences and ${ }^{3}$ Sense Organs, Sapienza University of Rome, I-00186 Rome, Italy
}

Received December 31, 2017; Accepted May 17, 2018

DOI: $10.3892 / \mathrm{ol} .2018 .9140$

\begin{abstract}
Patients affected by aggressive neoplasms with a high propensity to metastasize to the skin, including some types of head and neck cancer, may benefit from electrochemotherapy, a modality that combines the electroporation of cell membranes and chemotherapy to facilitate the transport of non-permeant molecules into cells; the host immune response consequently participates in achieving the abolition of tumors. Electrochemotherapy can be successfully used for skin metastases of head and neck tumors and, with some limitations, for primary and relapsing neoplasms; it can also be applied on an outpatient basis with a favorable cost-benefit ratio and it is a repeatable treatment that, if necessary, can be followed by traditional antineoplastic therapies. Although still a palliative treatment, the good level of tolerability and the high success rates of electrochemotherapy make it worth consideration among treatment options in selected patients.
\end{abstract}

\section{Contents}

1. Introduction

2. Electroporation and antineoplastic agents for head and neck cancer

3. Electric field and electrodes

4. Injection site, timing and drug dosage

5. Vascular lock

6. Immune response

7. Selectivity towards tumor cells, treatment protocols and follow up

8. Side effects

9. Treatment outcomes

Correspondence to: Dr Massimo Ralli, Department of Oral and Maxillofacial Sciences, Sapienza University of Rome, 155 Viale del Policlinico, I-00186 Rome, Italy

E-mail: massimo.ralli@uniroma1.it

Key words: head and neck cancer, skin metastasis, electrochemotherapy, electroporation, immune response
10. Discussion

11. Conclusions

\section{Introduction}

Electrochemotherapy (ECT) is an emerging skin-directed therapy with elevated cytotoxic activity and antivascular effects (1). ECT was first introduced in the late 1980s and has now evolved into a clinically verified treatment approach for cutaneous and subcutaneous tumors and has recently been extended to the treatment of deep-seated tumors $(1,2)$. ECT is the combination of electroporation (EP), as a mean to facilitate transporting low-permeant or nonpermeant anticancer drugs into tumor cells, and chemotherapy (3). EP is based on the application of intense and short electric pulses that make the cell membrane permeable, allowing for the penetration of different substances directly into the cytosol $(4,5)$. This technique has also been used in vitro to load dyes, DNA, RNA, ions and proteins into cells $(6,7)$. Radiotracers, drugs and oligonucleotides have been loaded into cells in vivo (8) and EP is used as an efficient non-viral approach for gene therapy $(9,10)$. The basic concept of ECT is shown in Fig. 1.

ECT is routinely used for cutaneous and subcutaneous tumors, including skin metastases of head and neck neoplasms, basal cell and Merkel cell carcinoma, Kaposi sarcoma, chronic lymphocytic leukemia infiltration and melanoma metastases due to its safety, effectiveness, organ sparing due to limited toxicity, cost-effectiveness, low-risk repeatability, and ready integration as neoadjuvant treatment (11).

This review paper aims to discuss advantages and limitations of the applications of ECT in head and neck cancer, with special attention to future clinical and research perspectives.

\section{Electroporation and antineoplastic agents for head and neck cancer}

EP and irreversible cell death are possible outcomes of cells or tissues being exposed to direct currents (12). If a cell is exposed to an electric field that is too large, the electroporated state is irreversible, and cell death follows (13). The application of electric pulses with higher amplitudes (14) or nanopulses (15) leads to the irreversible electroporation of 
cells and, consequently, to cell death, and has been suggested instead of ECT for tumor ablation; however, this technology is still under development.

The description of the phenomena occurring at the cell membrane level is still incomplete. One of the most accepted theories posits the generation of hydrophilic pores that transport molecules across cell membrane (12). However, these pores have yet to be observed in the membranes of cells submitted to effective electric pulses. Other theories hypothesize that there are no pores, and water enters the membrane through defects in its structure; the permeability coefficient of hydrophilic molecules such as bleomycin or cisplatin is favored by hydration of the membranes (16). Through these permeation structures, diffusion enables cell entry by non-permeant molecules $(16,17)$.

Bleomycin is a medication commonly used for the treatment of head and neck cancer. The study of Pron et al (18) identified a bleomycin-binding plasma membrane protein complex that entered the cell through endocytotic vesicles; however, it is still unknown as to why only a few molecules of bleomycin reach the DNA (19). The cytotoxicity of bleomycin can be enhanced 300 to 700 -fold by EP $(20,21)$ and, once in the cytosol, bleomycin has been reported to damage the DNA of target cells $(22,23)$.

Cisplatin, another common antineoplastic agent, has a permeabilization coefficient through the plasma membrane by passive diffusion of $<50 \%$, whereas the remainder is transported by carrier molecules (24). EP enables an increase of cisplatin cytotoxicity up to 80 -fold by increasing the flux and accumulation of the drug in cells (25). This increase in cisplatin uptake and DNA adduct generation is significant; however, it is still lower than bleomycin (26). Consequently, bleomycin is the drug most commonly used in clinical trials (27).

Bleomycin was isolated from the culture broth of the fungus Streptomyces verticillus collected from the soil in a coalmine in Japan (28). It is a family of at least 13 small water-soluble glycopeptide antibiotics, and the antineoplastic action of bleomycin is employed in the treatment of, among others, Hodgkin's disease, non-Hodgkin's lymphoma and testicular cancer $(29,30)$. Bleomycin breaks single- and double-stranded DNA, creating DNA fragmentation, chromosomal gaps and deletions; a previous study demonstrated 300 -fold increased toxicity from double-strand DNA breaks compared with single-strand breaks (31).

In 1991, the Institut Gustave Roussy (Paris) conducted the first clinical trial of ECT with bleomycin, in 8 patients with progressive or recurrent head and neck squamous cell carcinoma $(32,33)$. Subsequent studies have focused on treating head and neck cancer, including squamous cell carcinoma, adenoid cystic carcinoma and adenocarcinoma, basal cell carcinoma, malignant melanoma and adenocarcinoma of the breast $(4,5,26,27,29,32-34)$.

\section{Electric field and electrodes}

The pulses used in ECT are typically square wave electric pulses of $\sim 100 \mu$ s using a field strength of $1300 \mathrm{~V} / \mathrm{cm}(34,35)$. Pulses are grouped in runs of 4,6 , or 8 . Small tumors may be treated with a single run, while larger tumors require moving the electrodes step-by-step according to the permeabilization coefficient for EP of the whole target area (35).
There are two types of electrodes, plate electrodes and needle electrodes (35). Treatment of superficial lesions, such as those of the skin, are typically performed with plate electrodes. The depth of penetration of the electric field is small and is subject to the distance between the electrodes; the greater the distance is, the deeper the penetration of the electric field into the tissue (36). Needle electrodes can be positioned either in two parallel rows or in a circular array (37). In contrast to plate electrodes, needle electrodes must be inserted throughout the tumor tissue up to the deep tumor border (38).

With either electrode type, the highest electric field can be located around and between electrodes, which reduces quickly once outside of the electrode array. Such arrays may be circular or consist of two parallel rows. Thus, if the tumor is larger than the distance between the electrodes, moving and placing electrodes adjacently for each consecutive electric pulse application can efficiently treat the entire tumor (37). Deep-seated head and neck tumors typically require long single-needle electrodes; tumor placement and regional anatomy render covering the entire neoplasm with standard electrodes impractical (2).

\section{Injection site, timing and drug dosage}

The efficacy of ECT depends on guaranteeing drug presence in the tumor at the time of application. Bleomycin can be delivered intratumorally or systemically, in one clinical study, an intra-arterial injection of bleomycin was performed (39). The comparatively limited increase in efficacy of ECT with intravenous cisplatin (40), especially in head and neck metastases, has consequently limited clinical interest. Therefore, cisplatin has hence been confined to administration via the intratumoral route.

For systemic delivery, pulses require administration during the pharmacokinetic peak, which is between 8-28 min following drug administration (39). Intratumoral delivery must be performed between 1-10 min from drug delivery for maximum treatment efficacy $(41,42)$.

The intravenous injection of bleomycin requires a dose of $15,000 \mathrm{IU} / \mathrm{m}^{2}$; the neoplasm volume determines doses for intratumoral injection comprising of $\sim 500 \mathrm{IU} / \mathrm{cm}^{3}$ bleomycin, and $1 \mathrm{mg} / \mathrm{cm}^{3}$ cisplatin (43). Intratumoral administration requires a smaller dose of bleomycin than that required for intravenous administration and larger-volume tumors are generally thought to be more readily treated by intravenous than intratumoral administration; however, intratumoral administration may provide more efficacious treatment for poorly-vascularized tumors (39-43).

\section{Vascular lock}

Blood flow changes can occur following the in vivo delivery of electric pulses (44). In normal tissues, these effects appear as a transient hypoperfusion. The vascular effect implies that at the time of cell permeabilization, the drug is withheld within the electroporated area by the 'vascular lock' (44-46). Furthermore, the return to baseline blood flow levels in tumors may take hours, a much longer time than for normal tissue in which it may take minutes (44). 
A

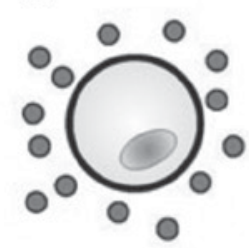

B

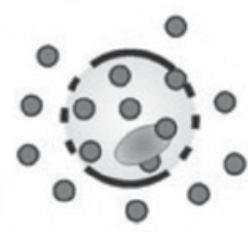

C

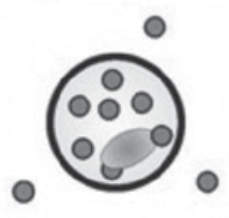

D

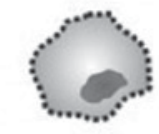

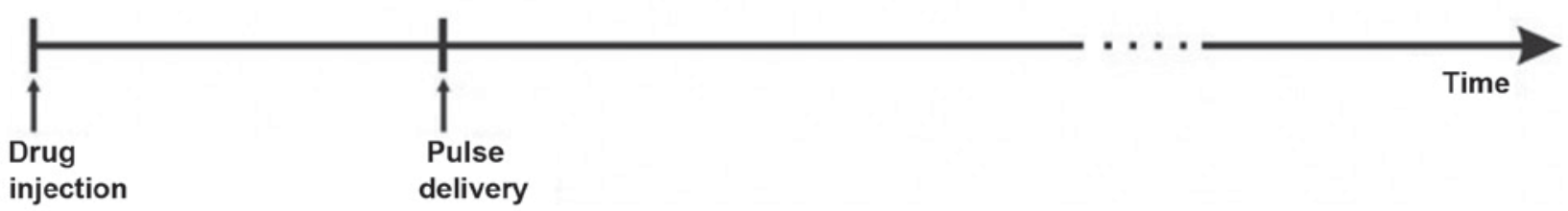

Figure 1. Basic concept of electrochemotherapy. (A) Following injection, drug surrounds the cell, (B) after the delivery of pulses, there is the formation of pores and the drug enters the cells, (C) The membrane reseals, leaving the drug is trapped inside the cell. (D) The drug kills neoplastic cells. From: Miklavčič et al (88).

These short-term vascular effects caused by the electric pulses are amplified in antitumor ECT. This is because the tumor endothelial cells are also dividing cells that can be destroyed by a combination of the drugs and the electric pulses (46). The mid- and long-term antivascular effects of ECT could therefore result from the killing of tumor endothelial cells, which would prevent the rapid reorganization of the tumor vasculature. Consequently, an almost permanent extremely hypoxic environment is created following nodule treatment by ECT (44-46), which may also contribute to the highly efficient antitumor effects observed.

\section{Immune response}

In the early 1990s, shortly following the initial preclinical trials on ECT, host immune response demonstrated an involvement in post-electrochemotherapy cures (47). At that time, immunotherapy was based on the administration of biological response modifiers such as cytokines or lymphokines (47).

Several additional preclinical trials have demonstrated that ECT combined with immunotherapy enhanced local antitumor effects and achieved systemic effects in several experimental models, including a metastasizing murine tumor model (48), a non-metastasizing murine tumor model (49) and a carcinoma model transplanted into the liver of rabbits (50).

This combination therapy is an attractive possibility that requires further experimental and clinical development. Other immunostimulatory approaches can be considered; for example, Heller et al (51) evaluated the transfer of the interleukin (IL)-12 gene in combination with bleomycin delivery in mice. Other combinations with chemokines have been already explored, such as the association of ECT and Tumour Necrosis Factor $\alpha$ administration (52).

\section{Selectivity towards tumor cells, treatment protocols and follow up}

In the presently available literature, the majority of tumors treated with ECT were primary tumors or metastases; the majority are cutaneous nodules or subcutaneous tumors (26); however, treatments have also been reported for recurrent head and neck cancer (53) and neck lymph node metastases (54).
The tumor size in the examined literature ranged from malignant melanomas of $\sim 0.3 \mathrm{~cm}$ (55) to cutaneous nodules in head and neck squamous cell carcinomas of up to $5 \mathrm{~cm}$ (32), in addition to breast metastases with cutaneous infiltration measuring $8 \times 20 \mathrm{~cm}(39)$.

In the head and neck, a single ECT treatment may be sufficient for single or multiple tumor nodules, including head and neck metastases (56). This treatment may completely eradicate tumor nodules. Less dramatically effective treatment can be repeated as often as monthly. Larger tumors $>3 \mathrm{~cm}$ in size can be successfully treated by repetitive application of electric pulses to the tumor until the whole tumor area is covered (56).

The size or the volume of the tumor is necessary to evaluate response and to calculate the amount of bleomycin to inject when using intratumoral injection. Allegretti et al (53) measured tumor volumes with the formula for an ellipse $\mathrm{V}=\mathrm{abc} \pi / 6$, which some authors have reported to be the most accurate formula for estimating tumor volume $(57,58)$.

Different methods are used to evaluate the tumor response following ECT. A clinical evaluation of tumor size or tumor volume is often used $(59,60)$, while many authors supplement this with biopsy (61) and, in some cases, Computed Tomography, Positron Emission Tomography, or Magnetic Resonance Imaging (55-64).

Some authors have treated patients under general anesthesia or neuroleptanalgesia due to tumor localization, size or number of tumors. Head and neck tumors often require general anesthesia when localization is in a sensitive area or open surgery is indicated (56-58). When smaller tumors, such as skin metastases, are treated with ECT, local anesthesia may be sufficient; epinephrine may be administered with local anesthesia to add a beneficial vasoconstriction that impedes washout of any drug injected prior to EP (59).

\section{Side effects}

A common side effect during the ECT procedure is an involuntary muscle contraction when the electric pulse is applied, especially when the lesion is in the neck area. The contractions cease at the end of the pulse; it is generally painless, but patients may feel some discomfort (11). Occasionally, mild burning of the skin has been observed in patients treated with 
plate electrodes; however, this type of burning has not been observed with needle electrodes (59). Crusting over the treated area is part of the natural healing process.

When lesions are located in crucial functional head and neck areas, extensive tumor necrosis can be responsible for functional deficits such as dysphagia, fistula formation and loss of oral competence (65). Furthermore, repeated treatment of the scalp has been reported to be associated with poor spontaneous healing rates $(65,66)$.

Minor side effects of ECT include skin ulceration and hyperpigmentation, maculopapular rash, skin suppuration and odor, and headaches (66).

\section{Treatment outcomes}

The response of individual tumors was classified by Mali et al (62) as complete response (CR), partial response $(\mathrm{PR})$, no change (NC) or progressive disease (PD), according to the data reported in a systematic review and meta-analysis performed by the authors on 44 studies involving 1,894 tumors (62). In addition, the concept of objective response (OR, including CR and PR) and no response were introduced. However, the studies were performed with variable treatment protocols, different electrodes and electric pulse generators. Therefore, it was recommended to perform a prospective non-randomized multi-institutional study.

In 2006, the results of a consortium of four cancer centers gathered together in a European Standard Operating Procedures of Electrochemotherapy (ESOPE) project were published (63). The response to treatment following ECT was tested according to tumor type, drug used, route of administration and type of electrode. The study (63) provided the following results: i) A response rate of $85 \%$ was achieved for ECT-treated tumor nodules, irrespective of tumor histology, drug or route of administration used. The carcinomas treated most frequently were cutaneous and subcutaneous melanoma nodules, followed by breast cancer, colon cancer, squamous cell carcinoma of the skin, squamous cell carcinoma of the cervix, Kaposi and cutaneous leiomyosarcoma and subcutaneous tumor nodules. ii) The local tumor control rate for ECT 150 days after treatment was $88 \%$ with bleomycin administered intravenously, $73 \%$ with bleomycin administered intratumorally and $75 \%$ with cisplatin administered intratumorally. This demonstrated that the three approaches were equally effective in local tumor control (63).

The European Research on Electrochemotherapy in Head and Neck Cancer (EURECA) group has achieved promising results with ECT in skin and mucosal tumors of the head and neck. In fact, after one year of follow-up, a global Disease-Free Survival (DFS) of $89 \%$ was detected with different percentages depending on the histological type of the tumor. The DFS for malignant melanoma was $100 \%$, the DFS for basal cell carcinoma was $89 \%$ and the DFS for squamous cell carcinoma was $87 \%(64,65)$.

Another clinical study of EURECA group on recurrent mucosal head and neck tumors reported positive results with an objective response to ECT of $56 \%$ (CR, 19\%; PR, 37\%) (66). Table I presents the principal findings of ECT treatment in head and neck cancer $(2,27,32,39,53,65-82)$.

\section{Discussion}

Based on the presently available evidence, ECT may be considered for treating a large range of tumors, including skin metastases of the head and neck, treatment restrictions of primary cutaneous and subcutaneous tissue, as in melanoma and squamous cell carcinoma, means a viable therapeutic alternative is being overlooked (1-4). Examples for application include the oral and nasal cavity and pharyngeal-laryngeal lumen, and long single-needle electrodes allow for ECT of deep-seated tumors of the head and neck $(2,13-15)$. Electric pulses can permeabilize any living cell, and bleomycin and cisplatin may therefore be applied to DNA molecules, irrespective of the onco- or antioncogenes expressed by tumor cells $(5,6)$.

Recently, a multicenter retrospective analysis reviewed the cases of 19 patients who underwent ECT from July 2007 to May 2014 for superficial advanced angiosarcomas. The authors reported that after 2 months, an objective response was observed in 63\% patients, with 6-month disease stabilization in $47 \%$ of patients. Treatment was generally well tolerated; local symptom improvement included palliation of bleeding (26\%) and pain relief (32\%). Based on the results obtained in these patients, the authors concluded that ECT may represent a promising treatment for providing local tumor control and symptom palliation in patients with superficial angiosarcomas (83).

An effective ECT requires that electrodes are applied to ensure a complete cover of the entire neoplasm; this may result in the serial administration of pulses for complete coverage. Similarly, drug concentration and delivery must be calibrated for maximum clinical efficacy, including the effects of the electric pulses. ECT effectiveness therefore requires administration protocols that are systematically planned and scrupulously executed and accompanied by well-designed checklists and follow-up to ensure and measure effectiveness. These principles are irrespective of tumor or electrode type, or whether drugs are delivered systemically or locally (44-46).

ECT treatment is intrinsically local and effective treatment for the local control of tumor growth and is important in the treatment of cancer. Surgery and/or radio-chemotherapy remain the primary treatments for head and neck cancer; however, as previously demonstrated at the clinical stage, adjuvant ECT provides effective cytoreduction, allowing for subsequent surgeries to potentially become less invasive and traumatic (39). Other therapeutic combinations, such as radiotherapy, are also possible. In cases of local recurrences where no further curative treatment options are available, ECT may serve a central therapeutic role (54-56). Recently, our group reported an interesting case of squamous cell carcinoma of the head and neck with extensive skin metastases that was successfully treated with ECT, demonstrating that ECT may be an effective therapy for metastases or local squamous cell carcinoma recurrence (54). ECT can typically be applied in the outpatient setting with a favorable cost-benefit ratio as bleomycin and cisplatin are relatively low-cost, and ECT equipment is less expensive than ionizing radiation devices $(1-4,19,21)$.

Treatment of internal tumors using endoluminal electrodes is currently being explored (84). This technological development has the potential for treating head and neck tumors 


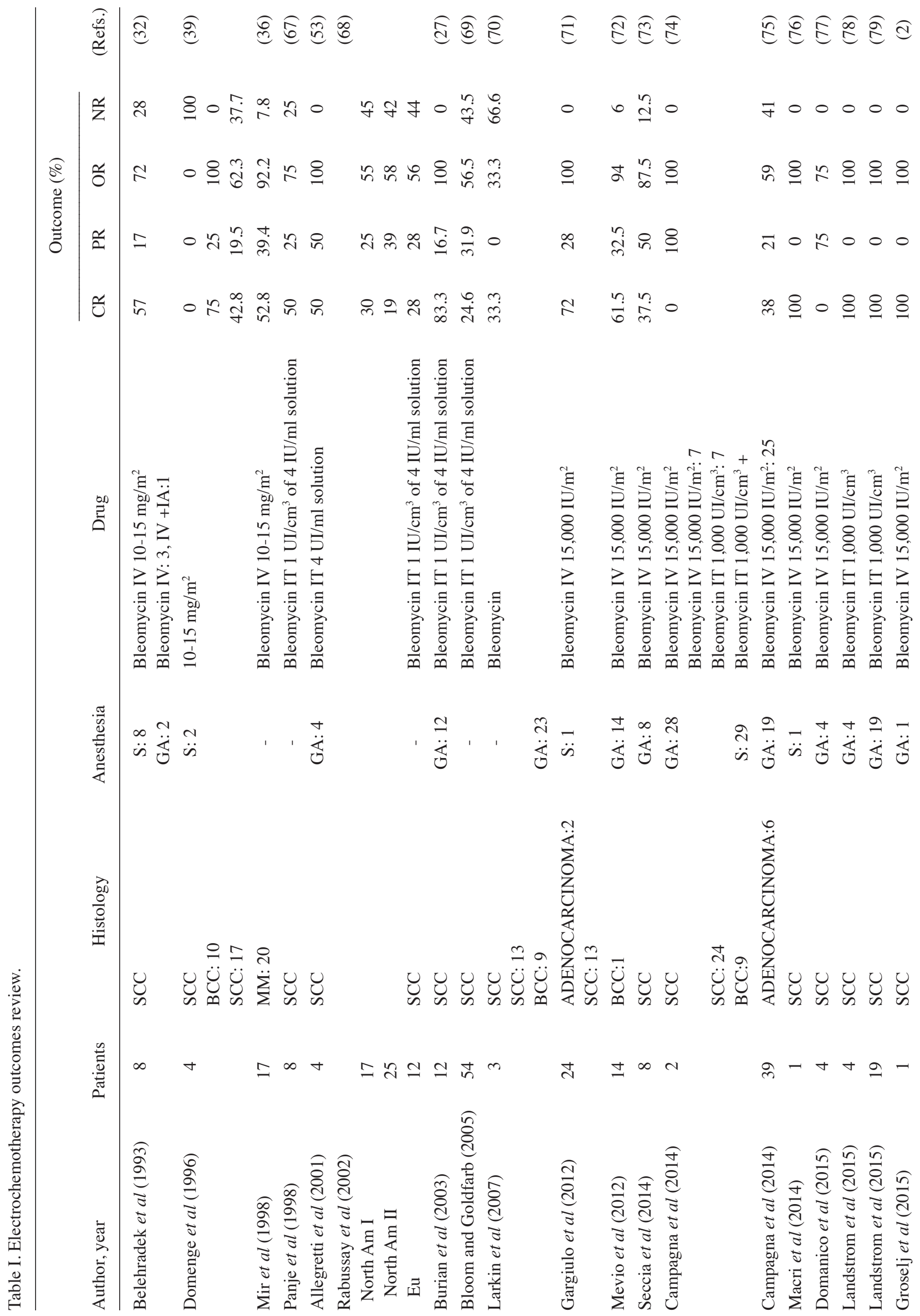


located in the parotid, submandibular and thyroid glands or in the latero-cervical space $(84,85)$.

Challenges in applying ECT to deep-seated tumors are represented by tissue conductivity, these include vasculature, necrosis, micro-heterogeneities, to the effects of EP on conductivity, determining the electrophoretic threshold (1). All such considerations dictate precise treatment planning and design, down to electrode placement, drug delivery, dosage and timing, to ensure the accuracy and robustness of a treatment plan (1).

Current evidence provides a basis for combining ECT with immunotherapy $(49-52,86)$. Immunomodulatory agents or the electro-transfer of genes coded for immunoregulatory proteins suggest the potential of a safer systemic cancer treatment, which is free from the adverse effects of current therapeutic modalities. ECT provides its own therapeutic and enhanced delivery benefits to this discussion, starting with current protocols and adapting them as the future demands. A broadening and extending of the range of indications for ECT can be anticipated for primary curative approaches (87).

\section{Conclusions}

ECT has demonstrated its safety and efficacy in skin metastases of head and neck tumors and, with some limitations, in primary and relapsing neoplasms of this region. ECT can be repeated as needed and does not interfere with or preclude subsequent therapy with primary treatment modes. Although at present, ECT is a palliative treatment, the high success rates of ECT and good level of tolerability, considered against the scarcity of alternative treatments in advanced stage cancers, make it worth consideration among treatment options in selected patients.

\section{Acknowledgements}

No applicable.

\section{Funding}

No funding was received.

\section{Availability of data and materials}

All data generated or analyzed during this study are included in this published article.

\section{Authors' contributions}

ADV and GA were responsible for the conception and design of the present study. MR undertook drafting of the manuscript, and LL and PM performed the analysis and interpretation of literature and data. FA performed manuscript revisions and MDV and AG were responsible for study design, critical revision of the manuscript, provided final approval.

\section{Ethical approval and consent to participate}

Not applicable. 


\section{Patient consent for publication}

Not applicable.

\section{Competing interests}

The authors declare that they have no competing interests.

\section{References}

1. Miklavcic D and Davalos RV: Electrochemotherapy (ECT) and irreversible electroporation (IRE) -advanced techniques for treating deep-seated tumors based on electroporation. Biomed Eng Online 14 (Suppl 3): I1, 2015.

2. Groselj A, Kos B, Cemazar M, Urbancic J, Kragelj G, Bosnjak M, Veberic B, Strojan P, Miklavcic D and Sersa G: Coupling treatment planning with navigation system: A new technological approach in treatment of head and neck tumors by electrochemotherapy. Biomed Eng Online 14 (Suppl 3): S2, 2015.

3. Mir LM, Orlowski S, Belehradek J Jr and Paoletti C: Electrochemotherapy potentiation of antitumour effect of bleomycin by local electric pulses. Eur J Cancer 27: 68-72, 1991.

4. Heller R, Gilbert R and Jaroszeski MJ: Clinical applications of electrochemotherapy. Adv Drug Deliv Rev 35: 119-129, 1999.

5. Heller R, Gilbert R and Jaroszeski MJ: Electrochemotherapy: An emerging drug delivery method for the treatment of cancer. Adv Drug Deliv Rev 26: 185-197, 1997.

6. Mir LM, Banoun H and Paoletti C: Introduction of definite amounts of nonpermeant molecules into living cells after electropermeabilization: Direct access to the cytosol. Exp Cell Res 175: 15-25, 1988.

7. Jaroszeski MJ, Dang V, Pottinger C, Hickey J, Gilbert R and Heller R: Toxicity of anticancer agents mediated by electroporation in vitro. Anticancer Drugs 11: 201-208, 2000.

8. Rols MP, Delteil C, Golzio M, Dumond P, Cros S and Teissie J: In vivo electrically mediated protein and gene transfer in murine melanoma. Nat Biotechnol 16: 168-171, 1998.

9. Mir LM, Bureau MF, Gehl J, Rangara R, Rouy D, Caillaud JM, Delaere P, Branellec D, Schwartz B and Scherman D High-efficiency gene transfer into skeletal muscle mediated by electric pulses. Proc Natl Acad Sci USA 96: 4262-4267, 1999.

10. Heller R, Jaroszeski M, Atkin A, Moradpour D, Gilbert R, Wands J and Nicolau C: In vivo gene electroinjection and expression in rat liver. FEBS Lett 389: 225-228, 1996.

11. Heller R, Jaroszeski MJ, Reintgen DS, Puleo CA, DeConti RC, Gilbert RA and Glass LF: Treatment of cutaneous and subcutaneous tumors with electrochemotherapy using intralesional bleomycin. Cancer 83: 148-157, 1998.

12. Orlowski S and Mir LM: Cell electropermeabilization: A new tool for biochemical and pharmacological studies. Biochim Biophys Acta 1154: 51-63, 1993.

13. Weaver JC: Electroporation: A general phenomenon for manipulating cells and tissues. J Cell Biochem 51: 426-435, 1993.

14. Edd JF, Horowitz L, Davalos RV, Mir LM and Rubinsky B: In vivo results of a new focal tissue ablation technique: Irreversible electroporation. IEEE Trans Biomed Eng 53: 1409-1415, 2006.

15. Nuccitelli R, Pliquett U, Chen X, Ford W, James Swanson R, Beebe SJ, Kolb JF and Schoenbach KH: Nanosecond pulsed electric fields cause melanomas to self-destruct. Biochem Biophys Res Commun 343: 351-360, 2006.

16. Weaver JC: Electroporation theory. Concepts and mechanisms. Methods Mol Biol 55: 3-28, 1995.

17. Neumann E, Schaefer-Ridder M, Wang Y and Hofschneider PH Gene transfer into mouse lyoma cells by electroporation in high electric fields. EMBO J 1: 841-845, 1982

18. Pron G, Belehradek J Jr and Mir LM: Identification of a plasma membrane protein that specifically binds bleomycin. Biochem Biophys Res Commun 194: 333-337, 1993.

19. Mir LM, Tounekti $O$ and Orlowski S: Bleomycin: Revival of an old drug. Gen Pharmacol 27: 745-748, 1996.

20. Gehl J, Skovsgaard T and Mir LM: Enhancement of cytotoxicity by electropermeabilization: An improved method for screening drugs. Anticancer Drugs 9: 319-325, 1998.

21. Orlowski S, Belehradek J Jr, Paoletti C and Mir LM: Transient electropermeabilization of cells in culture. Increase of the cytotoxicity of anticancer drugs. Biochem Pharmacol 37: 4727-4733, 1988.
22. Poddevin B, Orlowski S, Belehradek J Jr and Mir LM: Very high cytotoxicity of bleomycin introduced into the cytosol of cells in culture. Biochem Pharmacol 42 (Suppl): S67-S75, 1991.

23. Hall SW, Strong JE, Broughton A, Frazier ML and Benjamin RS: Bleomycin clinical pharmacology by radioimmunoassay. Cancer Chemother Pharmacol 9: 22-25, 1982.

24. Eljack ND, Ma HY, Drucker J, Shen C, Hambley TW, New EJ, Friedrich T and Clarke RJ: Mechanisms of cell uptake and toxicity of the anticancer drug cisplatin. Metallomics 6: 2126-2133, 2014.

25. Sersa G, Cemazar M and Miklavcic D: Antitumor effectiveness of electrochemotherapy with cis-diamminedichloroplatinum(II) in mice. Cancer Res 55: 3450-3455, 1995.

26. Rodriguez-Cuevas S, Barroso-Bravo S, Almanza-Estrada J, Cristobal-Martinez $\mathrm{L}$ and Gonzalez-Rodriguez E: Electrochemotherapy in primary and metastatic skin tumors: Phase II trial using intralesional bleomycin. Arch Med Res 32: 273-276, 2001.

27. Burian M, Formanek $\mathrm{M}$ and Regele H: Electroporation therapy in head and neck cancer. Acta Otolaryngol 123: 264-268, 2003.

28. Umezawa H, Maeda K, Takeuchi T and Okami Y: New antibiotics, bleomycin A and B. J Antibiot (Tokyo) 19: 200-209, 1966.

29. Dillman RO: Rationales for combining chemotherapy and biotherapy in the treatment of cancer. Mol Biother 2: 201-207, 1990.

30. Tounekti O, Pron G, Belehradek J Jr and Mir LM: Bleomycin, an apoptosis-mimetic drug that induces two types of cell death depending on the number of molecules internalized. Cancer Res 53: 5462-5469, 1993.

31. Tounekti O, Kenani A, Foray N, Orlowski S and Mir LM: The ratio of single- to double-strand DNA breaks and their absolute values determine cell death pathway. Br J Cancer 84: 1272-1279, 2001.

32. Belehradek M, Domenge C, Luboinski B, Orlowski S, Belehradek J Jr and Mir LM: Electrochemotherapy, a new antitumor treatment. First clinical phase I-II trial. Cancer 72: 3694-3700, 1993.

33. Mir LM, Belehradek M, Domenge C, Orlowski S, Poddevin B, Belehradek J Jr, Schwaab G, Luboinski B and Paoletti C: Electrochemotherapy, a new antitumor treatment: First clinical trial. C R Acad Sci III 313: 613-618, 1991 (In French).

34. Sersa G, Cufer T, Cemazar M, Rebersek M and Zvonimir R: Electrochemotherapy with bleomycin in the treatment of hypernephroma metastasis: Case report and literature review. Tumori 86: 163-165, 2000.

35. Puc M, Corovic S, Flisar K, Petkovsek M, Nastran J and Miklavcic D: Techniques of signal generation required for electropermeabilization. Survey of electropermeabilization devices. Bioelectrochemistry 64: 113-124, 2004.

36. Mir LM, Glass LF, Sersa G, Teissié J, Domenge C, Miklavcic D, Jaroszeski MJ, Orlowski S, Reintgen DS, RudolfZ, et al: Effective treatment of cutaneous and subcutaneous malignant tumours by electrochemotherapy. Br J Cancer 77: 2336-2342, 1998.

37. Mir LM, Gehld J, Sersae G, et al: Standard operating procedures of the electrochemotherapy: Instructions for the use of bleomycin or cisplatin administered either systemically or locally and electric pulses delivered by the Cliniporator by means of invasive or non-invasive electrodes. EJC Supplements 4: 14-25, 2006.

38. Miklavcic D, Corovic S, Pucihar G and Pavselj N: Importance of tumour coverage by sufficiently high local electric field for effective electrochemotherapy. Eur J Cancer Suppl 4: 45-51, 2006.

39. Domenge C, Orlowski S, Luboinski B, De Baere T, Schwaab G, Belehradek J Jr and Mir LM: Antitumor electrochemotherapy: New advances in the clinical protocol. Cancer 77: 956-963, 1996.

40. Sersa G, Stabuc B, Cemazar M, Miklavcic D and Rudolf Z: Electrochemotherapy with cisplatin: The systemic antitumour effectiveness of cisplatin can be potentiated locally by the application of electric pulses in the treatment of malignant melanoma skin metastases. Melanoma Res 10: 381-385, 2000.

41. Cemazar M, Milacic R, Miklavcic D, Dolzan V and Sersa G: Intratumoral cisplatin administration in electrochemotherapy: Antitumor effectiveness, sequence dependence and platinum content. Anticancer Drugs 9: 525-530, 1998.

42. Heller R, Jaroszeski M, Perrott R, Messina J and Gilbert R: Effective treatment of B16 melanoma by direct delivery of bleomycin using electrochemotherapy. Melanoma Res 7: 10-18, 1997.

43. Mir LM: Electroporation-based gene therapy: Recent evolution in the mechanism description and technology developments. Methods Mol Biol 1121: 3-23, 2014. 
44. Sersa G, Cemazar M, Parkins CS and Chaplin DJ: Tumour blood flow changes induced by application of electric pulses. Eur J Cancer 35: 672-677, 1999.

45. Gehl J and Geertsen PF: Efficient palliation of haemorrhaging malignant melanoma skin metastases by electrochemotherapy. Melanoma Res 10: 585-589, 2000.

46. Cemazar M, Parkins CS, Holder AL, Chaplin DJ, Tozer GM and Sersa G: Electroporation of human microvascular endothelial cells: Evidence for an anti-vascular mechanism of electrochemotherapy. Br J Cancer 84: 565-570, 2001.

47. Mir LM, Orlowski S, Poddevin B and Belehradek J Jr: Electrochemotherapy tumor treatment is improved by interleukin-2 stimulation of the host's defenses. Eur Cytokine Netw 3: 331-334, 1992.

48. Orlowski S, An D, Belehradek J Jr and Mir LM: Antimetastatic effects of electrochemotherapy and of histoincompatible interleukin-2-secreting cells in the murine Lewis lung tumor. Anticancer Drugs 9: 551-556, 1998.

49. Mir LM, Roth C, Orlowski S, Quintin-Colonna F, Fradelizi D, Belehradek J Jr and Kourilsky P: Systemic antitumor effects of electrochemotherapy combined with histoincompatible cells secreting interleukin-2. J Immunother Emphasis Tumor Immunol 17: 30-38, 1995.

50. Ramirez LH, Orlowski S, An D, Bindoula G, Dzodic R, Ardouin P, Bognel C, Belehradek J Jr, Munck JN and Mir LM: Electrochemotherapy on liver tumours in rabbits. Br J Cancer 77 2104-2111, 1998.

51. Heller L, Pottinger C, Jaroszeski MJ, Gilbert R and Heller R: In vivo electroporation of plasmids encoding GM-CSF or interleukin-2 into existing B16 melanomas combined with electrochemotherapy induces long-term antitumour immunity. Melanoma Res 10: 577-583, 2000.

52. Sersa G, Cemazar M, Menart V, Gaberc-Porekar V and Miklavcic D: Anti-tumor effectiveness of electrochemotherapy with bleomycin is increased by TNF-alpha on SA-1 tumors in mice. Cancer Lett 116: 85-92, 1997.

53. Allegretti JP and Panje WR: Electroporation therapy for head and neck cancer including carotid artery involvement. Laryngoscope 111: 52-56, 2001.

54. De Virgilio A, Fusconi M, Greco A and de Vincentiis M: The role of electrochemotherapy in the treatment of metastatic head and neck cancer. Tumori 99: 634, 2013.

55. Rols MP, Bachaud JM, Giraud P, Chevreau C, Roche H and Teissie J: Electrochemotherapy of cutaneous metastases in malignant melanoma. Melanoma Res 10: 468-474, 2000.

56. Snoj M, Cemazar M, Slekovec Kolar B and Sersa G: Effective treatment of multiple unresectable skin melanoma metastases by electrochemotherapy. Croat Med J 48: 391-395, 2007.

57. Wapnir IL, Wartenberg DE and Greco RS: Three dimensional staging of breast cancer. Breast Cancer Res Treat 41: 15-19, 1996

58. Tomayko MM and Reynolds CP: Determination of subcutaneous tumor size in athymic (nude) mice. Cancer Chemother Pharmacol 24: 148-154, 1989.

59. Heller R, Jaroszeski MJ, Glass LF, Messina JL, Rapaport DP, DeConti RC, Fenske NA, Gilbert RA, Mir LM and Reintgen DS: Phase I/II trial for the treatment of cutaneous and subcutaneous tumors using electrochemotherapy. Cancer 77: 964-971, 1996.

60. Kubota Y, Mir LM, Nakada T, Sasagawa I, Suzuki H and Aoyama N: Successful treatment of metastatic skin lesions with electrochemotherapy. J Urol 160: 1426, 1998.

61. Glass LF, Pepine ML, Fenske NA, Jaroszeski M, Reintgen DS and Heller R: Bleomycin-mediated electrochemotherapy of metastatic melanoma. Arch Dermatol 132: 1353-1357, 1996.

62. Mali B, Jarm T, Snoj M, Sersa G and Miklavcic D: Antitumor effectiveness of electrochemotherapy: A systematic review and meta-analysis. Eur J Surg Oncol 39: 4-16, 2013.

63. Marty M, Sersa G and Garbay JR: Electrochemotherapy-An easy, highly effective and safe treatment of cutaneous and subcutaneous metastases: Results of ESOPE (European Standard Operating Procedures of Electrochemotherapy) study. Eur J Cancer Suppl 4: 3-13, 2006.

64. Sersa G: The state-of-the-art of electrochemotherapy before the ESOPE study: Advantages and clinical uses. Eur J Cancer Suppl 4: 52-59, 2006.

65. Bertino G, Sersa G, De Terlizzi F, Occhini A, Plaschke CC, Groselj A, Langdon C, Grau JJ, McCaul JA, Heuveling D, et al: European research on electrochemotherapy in head and neck Cancer (EURECA) project: Results of the treatment of skin cancer. Eur J Cancer 63: 41-52, 2016.
66. Plaschke CC, Bertino G, McCaul JA, Grau JJ, de Bree R, Sersa G, Occhini A, Groselj A, Langdon C, Heuveling DA, et al: European Research on Electrochemotherapy in Head and Neck Cancer (EURECA) project: Results from the treatment of mucosal cancers. Eur J Cancer 87: 172-181, 2017.

67. Panje WR, Hier MP, Garman GR, Harrell E, Goldman A and Bloch I: Electroporation therapy of head and neck cancer. Ann Otol Rhinol Laryngol 107: 779-785, 1998.

68. Rabussay DP, Nanda GS and Goldfarb PM: Enhancing the effectiveness of drug-based cancer therapy by electroporation (electropermeabilization). Technol Cancer Res Treat 1: 71-82,2002.

69. Bloom DC and Goldfarb PM: The role of intratumour therapy with electroporation and bleomycin in the management of advanced squamous cell carcinoma of the head and neck. Eur J Surg Oncol 31: 1029-1035, 2005.

70. Larkin JO, Collins CG, Aarons S, Tangney M, Whelan M, O'Reily S, Breathnach O, Soden DM and O'Sullivan GC: Electrochemotherapy: Aspects of preclinical development and early clinical experience. Ann Surg 245: 460-479, 2007.

71. Gargiulo M, Papa A, Capasso P, Moio M, Cubicciotti E and Parascandolo S: Electrochemotherapy for non-melanoma head and neck cancers: Clinical outcomes in 25 patients. Ann Surg 255: 1158-1164, 2012

72. Mevio N, Bertino G, Occhini A, Scelsi D, Tagliabue M, Mura F and Benazzo M: Electrochemotherapy for the treatment of recurrent head and neck cancers: Preliminary results. Tumori 98: 308-313, 2012.

73. Seccia V, Muscatello L, Dallan I, Bajraktari A, Briganti T, Ursino S, Galli L, Falcone A and Sellari-Franceschini S: Electrochemotherapy and its controversial results in patients with head and neck cancer. Anticancer Res 34: 967-972, 2014.

74. Campana LG, Bertino G, Rossi CR, Occhini A, Rossi M, Valpione S and Benazzo M: The value of electrochemotherapy in the treatment of peristomal tumors. Eur J Surg Oncol 40: 260-262, 2014.

75. Campana LG, Mali B, Sersa G, Valpione S, Giorgi CA, Strojan P, Miklavcic D and Rossi CR: Electrochemotherapy in non-melanoma head and neck cancers: A retrospective analysis of the treated cases. Br J Oral Maxillofac Surg 52: 957-964, 2014.

76. Macri GF, Greco A, Gallo A, Fusconi M, Marinelli C and de Vincentiis M: Use of electrochemotherapy in a case of neck skin metastasis of oral squamous cell carcinoma: Case report and considerations. Head Neck 36: E86-E90, 2014.

77. Domanico R, Trapasso S, Santoro M, Pingitore D and Allegra E: Electrochemotherapy in combination with chemoradiotherapy in the treatment of oral carcinomas in advanced stages of disease: Efficacy, safety, and clinical outcomes in a small number of selected cases. Drug Des Devel Ther 9: 1185-1191, 2015.

78. Landstrom FJ, Reizenstein JA, Nilsson CO, Beckerath MV, Löfgren AL, Adamsson GB and Möller C: Electrochemotherapy-possible benefits and limitations to its use in the head and neck region. Acta Otolaryngol 135: 90-95, 2015.

79. Landstrom FJ, Reizenstein J, Adamsson GB, Beckerath Mv and Möller C: Long-term follow-up in patients treated with curative electrochemotherapy for cancer in the oral cavity and oropharynx. Acta Otolaryngol 135: 1070-1078, 2015.

80. Rotunno R, Marenco F, Ribero S, Calvieri S, Amerio P, Curatolo P and Quaglino P: Electrochemotherapy in non-melanoma head and neck skin cancers: A three-center experience and review of the literature. G Ital Dermatol Venereol 151: 610-618, 2016.

81. Montuori M, Santurro L, Feliziani A, DE Sanctis F, Ricciardi E, Gaudio D, Campione E, Bianchi L, Silvi MB and Rossi P: Electrochemotherapy for basocellular and squamocellular head and neck cancer: Preliminary experience in Day Surgery Unit. G Ital Dermatol Venereol 153: 19-25, 2018.

82. Groselj A, Bosnjak M, Strojan P, Krzan M, Cemazar M and Sersa G: Efficiency of electrochemotherapy with reduced bleomycin dose in the treatment of nonmelanoma head and neck skin cancer: Preliminary results. Head Neck 40: 120-25, 2018.

83. Guida M, Campana LG, Curatolo P, Strippoli S, Bonadies A, Grilz G, Cabula C, Rotunno R, Bucher S, Solari N, et al: Local treatment with electrochemotherapy of superficial angiosarcomas: Efficacy and safety results from a multi-institutional retrospective study. J Surg Oncol 114: 246-253, 2016.

84. Jahangeer S, Forde P, Soden D and Hinchion J: Review of current thermal ablation treatment for lung cancer and the potential of electrochemotherapy as a means for treatment of lung tumours. Cancer Treat Rev 39: 862-871, 2013. 
85. Sersa G, Cufer T, Paulin SM, Cemazar M and Snoj M: Electrochemotherapy of chest wall breast cancer recurrence. Cancer Treat Rev 38: 379-386, 2012.

86. Calvet CY and Mir LM: The promising alliance of anti-cancer electrochemotherapy with immunotherapy. Cancer Metastasis Rev 35: 165-177, 2016.

87. Lenzi R, Muscatello L, Saibene AM, Felisati G and Pipolo C: The controversial role of electrochemotherapy in head and neck cancer: A systematic review of the literature. Eur Arch Otorhinolaryngol 274: 2389-2394, 2017.
88. Miklavčič D, Serša G, Brecelj E, Gehl J, Soden D Bianchi G, Ruggieri P, Rossi CR, Campana LG and Jarm T: Electrochemotherapy: technological advancements for efficient electroporation-based treatment of internal tumors. Med Biol Eng Comput 50: 1213-1225, 2012. 